\title{
RESEARCH
}

Open Access

\section{Higher titer hepatitis B core antibody predicts a higher risk of liver metastases and worse survival in patients with colorectal cancer}

Ziyao Li ${ }^{1,2}$, Shaofei $\mathrm{Li}^{1,2}$, Hangbo Tao ${ }^{1,2}$, Yixiang Zhan ${ }^{1,2}$, Kemin $\mathrm{Ni}^{1,2}$, Jianfeng Gong ${ }^{3}$ and Guoxun $\mathrm{Li}^{1^{*}}$ (1)

\begin{abstract}
Background: There have been controversial voices on if hepatitis B virus infection decreases the risk of colorectal liver metastases or not. This study aims to the find the association between HBV infection and postoperative survival of colorectal cancer and the risk of liver metastases in colorectal cancer patients.

Methods: Patients who underwent curative surgical resection for colorectal cancer between January 2011 and December 2012 were included. Patients were grouped according to anti-HBc. Differences in overall survival, time to progress, and hepatic metastasis-free survival between groups and significant predictors were analyzed.

Results: Three hundred twenty-seven colorectal cancer patients were comprised of 202 anti-HBc negative cases and 125 anti-HBC positive cases, and anti-HBC positive cases were further divided into high-titer anti-HBC group (39) and low-titer anti-HBC group (86). The high-titer anti-HBC group had significantly worse overall survival (5-Yr, 65.45\% vs. $80.06 \%$; $P<.001)$, time to progress $(5-Y$ r, $44.26 \%$ vs. 84.73\%; $P<.001)$, and hepatic metastasis-free survival (5-Yr, $82.44 \%$ vs. $94.58 \% ; P=.029)$ than the low-titer group. Multivariate model showed anti-HBC $\geq 8.8 \mathrm{~S} / \mathrm{CO}$ was correlated with poor overall survival (HR, 3.510; $95 \% \mathrm{Cl}, 1.718-7.17 ; P<.001)$, time to progress $(\mathrm{HR}, 5.747 ; 95 \% \mathrm{Cl}$, 2.789-11.842; $P<.001)$, and hepatic metastasis-free survival $(H R, 3.754 ; 95 \% C l, 1.054-13.369 ; P=.041)$ in the anti$\mathrm{HBC}$ positive cases.
\end{abstract}

Conclusions: Higher titer anti-HBC predicts a potential higher risk of liver metastases and a worse survival in anti$\mathrm{HBC}$ positive colorectal cancer patients.

Keywords: Hepatitis B virus, Hepatitis B core antibody, Colorectal cancer, Colorectal liver metastases

* Correspondence: liguoxun6@163.com

'Department of Colorectal Surgery, Tianjin Union Medical Center, No. 190 Jieyuan street, Hongqiao District, Tianjin 300121, China

Full list of author information is available at the end of the article

C C The Author(s). 2021 Open Access This article is licensed under a Creative Commons Attribution 4.0 International License, which permits use, sharing, adaptation, distribution and reproduction in any medium or format, as long as you give appropriate credit to the original author(s) and the source, provide a link to the Creative Commons licence, and indicate if changes were made. The images or other third party material in this article are included in the article's Creative Commons licence, unless indicated otherwise in a credit line to the material. If material is not included in the article's Creative Commons licence and your intended use is not permitted by statutory regulation or exceeds the permitted use, you will need to obtain permission directly from the copyright holder. To view a copy of this licence, visit http://creativecommons.org/licenses/by/4.0/. The Creative Commons Public Domain Dedication waiver (http://creativecommons.org/publicdomain/zero/1.0/) applies to the data made available in this article, unless otherwise stated in a credit line to the data. 


\section{Background}

Colorectal cancer (CRC) is the third most common carcinoma in the world [1]. The 5-year relative survival rate for CRC is $65 \%$ [2]. Distant metastases are major cause of death and liver is the most common metastatic site [3].

Inflammation has close relationship with the forming of tumor. In the nineteenth century, German doctor Rudolf Virchow [4] first observed leukocytes infiltration in tumor tissue. Then, it was expounded that the leukocytes infiltrated in tumor tissue could generate inflammatory mediators, thereby forming inflammatory microenvironment in tumor tissue which was further founded to stimulate the development of tumor [5-7]. Chronic inflammation could be sustained by the longterm activity of harmful microorganisms in the human body $[8,9]$, which may promote tumor formation and development.

$\mathrm{HBV}$ is the virus that leads to inflammation and necrosis of hepatocytes during infection, and it is one of the leading public health problems in China [10]. As a consequence, there are a large number of CRC patients accompanied by HBV. However, whether HBV infection affects the incidence of colorectal liver metastases (CRLM) remains unclear.

As almost all of the patients generate hepatitis $\mathrm{B}$ core antibody (anti-HBc) after HBV infection, hepatitis B core antibody (anti-HBc) is recognized as the most sensitive serum marker [11] in the course of HBV infection. Therefore, anti-HBc was used as a marker of recent or previously infection of HBV. Furthermore, as the titer of anti-HBc showed positive correlation with the activity of HBV replication $[12,13]$, the relationship between HBV replication and outcomes of the crowd in the study was also analyzed.

\section{Methods}

\section{Patients}

A retrospective analysis was conducted by reviewing the clinicopathological data of CRC patients who underwent curative resection from January 2011 to December 2012 at the Tianjin Union Medical Center. Patients who met the following criteria were enrolled: (1) histologically confirmed colorectal malignancy, (2) TNM stage II or III, (3) no evidence of distant metastases was found before the operation, (4) R0 resection for primary lesion, and (5) aged between 40 and 75 years. All clinicopathological data, including clinicopathological features, tumor characteristics, and laboratory examinations, were obtained from medical records and follow-up system of Tianjin Union Medical Center. All the patients included were staged according to AJCC Cancer Staging Manual, 7th edition.

\section{Treatment}

Patients with colon cancer received imaging examinations consisting of thoracic, abdominal, and pelvic computed tomography (CT), abdominal ultrasound, abdominal and/or pelvic magnetic resonance imaging (MRI) (if necessary), and colonoscopy before operation.

Patients with rectal cancer received imaging examinations consisting of thoracic, abdominal, and pelvic CT, abdominal ultrasound, pelvic MRI, abdominal MRI (if necessary), and colonoscopy before operation.

The primary colorectal malignancy was radically resected from all eligible patients according to the principle of total mesorectal excision (TME) or complete mesocolic excision (CME). Depending on patients' conditions, neoadjuvant therapy and adjuvant treatment was determined by the multidisciplinary team (MDT). For colon cancer, neoadjuvant FOLFOX or CAPEOX was considered for bulky nodal disease or clinical T4b; neoadjuvant radiation therapy (RT) with concurrent fluoropyrimidine (FU)-based chemotherapy was considered for initially unresectable or medically inoperable tumor to aid resectability; adjuvant treatment consisting FOLFOX, or CAPEOX, or capecitabine alone, or 5-FU/leucovorin, or observation was considered according to the pathologic stage. For the rectal cancer, neoadjuvant therapy consisting long-course chemotherapy/RT or short-course RT was considered according to clinical stage; FOLFOX, or CAPEOX, or infusional 5-FU/RT, or capecitabine/RT followed by FOLFOX or CAPEOX, or observation was considered for adjuvant treatment according to pathologic stage and clinical stage.

\section{Group}

All of the cases were grouped based on anti-HBc. Firstly, all cases were grouped into anti-HBc positive group and anti-HBc negative group. Moreover, the anti-HBc positive group was grouped into the high-titer anti-HBc group and the low-titer anti-HBc group by the cutoff point of $8.8 \mathrm{~S} / \mathrm{CO}$ which was calculated based on time to progress (TTP).

\section{Serologic assay for CRC patients}

All laboratory results, including biochemical tests, serum tumor markers, and HBV infection tests, were obtained within 1 week before the operation. Hepatitis B surface antigen (HBsAg), antibodies to hepatitis B surface antigen (anti-HBs), and anti-HBc were detected by electrochemical luminescence. Carcinoembryonic antigen (CEA) levels above $5 \mathrm{ng} / \mathrm{ml}$, carbohydrate antigen 19-9 (CA19-9) levels above $37 \mathrm{U} / \mathrm{ml}$, and anti-HBc levels above $1 \mathrm{~S} / \mathrm{CO}$ were considered to be elevated. 


\section{Follow-up of patients}

All patients were followed up after hospital discharge. The patients were followed up every 3 months in the first 2 years after surgery and then semi-annually during the third to the fifth year. The follow-up evaluation included a routine physical, blood test, tests for the tumor markers CEA and CA19-9, and abdominal ultrasonography. Thoracic, abdominal, and pelvic computed tomography (CT) were performed annually. Colonoscopy was performed in 1 year after surgery except if no preoperative colonoscopy due to obstructing lesion, colonoscopy in 6 months. If advanced adenoma was founded, repeat it in 1 year; otherwise, repeat it in 3 years, then every 5 years. Magnetic resonance imaging (MRI) was performed when necessary. The follow-up period was terminated in July 2019.

\section{Non-invasive prediction methods calculation formulae}

The following fibrosis 4 score (FIB-4) equations was used to evaluate the extent of fibrosis $[14,15]$. Calculation formulae of FIB-4: FIB- $4=\frac{\operatorname{Age}(y e a r s) \times \operatorname{AST}(\mathrm{U} / \mathrm{L})}{\text { Platelets }\left(10^{9} / \mathrm{L}\right) \times \sqrt{\operatorname{ALT}(\mathrm{U} / \mathrm{L})}}$ [15]; neutrophil to lymphocyte ratio (NLR) was used to indicate the extent of inflammatory response. NLR $=\frac{\text { Neutrophil }\left(10^{9} / \mathrm{L}\right)}{\operatorname{Lymphocyte}\left(10^{9} / \mathrm{L}\right)}[16]$. The cutoff points for FIB-4 and NLR are 1.45 and 3.4, respectively.

\section{Statistical methods}

Continuous variables are presented as means \pm standard deviation (SD). Categorical variables are shown as the number of cases and percentages. Comparisons for continuous variables were performed using Student's $t$ test or Mann-Whitney $U$ test. Chi-square test and Fisher's exact test was performed for the categorical variables. Overall survival (OS), TTP, and hepatic metastasis-free survival (HMFS) outcomes were compared using Kaplan-Meier curves. Log-rank test was used to determine statistical differences between curves. Univariate and multivariate analyses were performed by Cox proportional hazards regression models to determine the hazard ratio of each factor. Variables that were showed a significant univariate relationship with outcome were entered into the multivariate analysis. OS was defined from the date of surgery to the date of death or last follow-up. TTP was defined from the date of surgery to the date of disease progression. HMFS was defined from the date of surgery to the date of occurrence of hepatic metastases. The optimal cutoff point of NLR and anti-HBc are determined by X-tile 3.6.1 software (Yale University, New Haven, CT, USA) based on TTP. All statistical analyses were performed using SPSS 22.0 statistical software (IBM, NY, USA) and GraphPad Prism version 8.01 (GraphPad Software, Inc., La Jolla, CA, USA). A two- tailed $P$ value $<.05$ was interpreted as statistically significant.

\section{Results \\ Baseline characteristics of patients}

A total of 327 cases were qualified for the analyses. Among them, $202(61.8 \%)$ cases were anti-HBc negative and $125(38.2 \%)$ cases were anti-HBc positive including $8(2.4 \%) \mathrm{HBsAg}$ positive cases. The 125 anti-HBc positive cases were divided into two groups according to optimal cut-off point of anti-HBc titer $(8.8 \mathrm{~S} / \mathrm{CO}): 39$ $(31.2 \%)$ cases were classified into the high-titer anti-HBc group, while the remaining $86(68.8 \%)$ cases were classified into the low-titer anti-HBc group. The comparisons of baseline characteristics were shown in Table 1. No statistical difference between the anti-HBc positive and negative group was identified except for the gender proportion in which the proportion of male was significantly higher in the anti-HBc positive group than the anti-HBc negative group ( $68 \%$ vs. $55.4 \%, P=.027$ ). Besides, no significant difference was identified between the high-titer and low-titer anti-HBc group.

\section{Overall survival, time to progress, and hepatic metastasis- free survival difference according to anti-HBc status}

The mean follow-up period was $61.2 \pm 28.8$ months. Recurrence was observed in $84(25.7 \%)$ of 327 patients until the last follow-up. There were 30 (9.2\%) hepatic recurrences, 37 (11.3\%) lung recurrences, 11 (3.36\%) bone recurrences, $11(3.36 \%)$ pelvic recurrences, and $5(1.5 \%)$ instances of brain recurrences. The OS, TTP, and HMFS curves for the anti-HBc positive and negative groups are shown in Fig. 1. The 3-, 5- year OS (3-Yr, 87.72\% vs. $89.96 \%$; 5 -Yr, $75.51 \%$ vs. $80.43 \%$; $P=.395$; Fig. 1 A), TTP (3-Yr, $79.97 \%$ vs. $77.85 \%$; 5 -Yr, $71.66 \%$ vs. $74.20 \%$; $P=$ .524; Fig. 1B), and HMFS (3-Yr, $93.43 \%$ vs. $90.21 \%$; $5-\mathrm{Yr}$, $91.09 \%$ vs. $88.85 \%$; $P=.739$; Fig. $1 C$ ) did not differ between the two groups. In contrast, there are significant differences identified between the high-titer and lowtiter anti-HBc groups (Fig. 2). Patients in the high-titer anti-HBc group had worse OS (3-Yr, 78.74\% vs. $91.80 \%$; 5-Yr, $65.45 \%$ vs. $80.06 \%$; $P<0.001$; Fig. 2 A), TTP (3-Yr, $60.88 \%$ vs. $89.21 \%$; 5 -Yr, $44.26 \%$ vs. $84.73 \%$; $P<0.001$; Fig. 2B), and HMFS (3-Yr, $87.29 \%$ vs. $96.11 \%$; $5-\mathrm{Yr}$, $82.44 \%$ vs. $94.58 \% ; P=.029$; Fig. 2 C) than those in the low-titer anti-HBc group.

\section{Prognostic factors for OS, TTP, and HMFS}

Univariate and multivariate analyses of the prognostic factors for OS, TTP, and HMFS are presented in the Tables 2 and 3. For the CRC patients undergoing curative surgical resection, NLR $\geq 3.4$ (HR, 1.838; 95\% CI, 1.1193.02; $P=.016)$, CA19-9 > $37 \mathrm{U} / \mathrm{ml}(\mathrm{HR}, 2.111 ; 95 \% \mathrm{CI}$, 1.229-3.624; $P=.007)$, and stage III (HR, 3.511; 95\% CI, 
Table 1 Characteristics of the included patients

\begin{tabular}{|c|c|c|c|c|c|c|}
\hline Variable & $\begin{array}{l}\text { anti-HBc positive, } n \\
\text { (\%) }\end{array}$ & $\begin{array}{l}\text { anti-HBc negative, } n \\
(\%)\end{array}$ & $\begin{array}{l}P \\
\text { value }\end{array}$ & $\begin{array}{l}\text { High-titer anti-HBc, } n \\
(\%)\end{array}$ & $\begin{array}{l}\text { Low-titer anti-HBc, } n \\
\text { (\%) }\end{array}$ & $\begin{array}{l}P \\
\text { value }\end{array}$ \\
\hline$N$ & 125 & 202 & & 39 & 86 & \\
\hline Age (years) & $61.32 \pm 8.01$ & $60.61 \pm 7.55$ & 0.419 & $59.44 \pm 7.469$ & $62.17 \pm 8.147$ & 0.077 \\
\hline Gender & & & $0.027^{*}$ & & & 0.154 \\
\hline Male & $85(68)$ & $112(55.4)$ & & $23(59.0)$ & $62(72.1)$ & \\
\hline Female & $40(32)$ & $90(44.6)$ & & $16(41.0)$ & $24(27.9)$ & \\
\hline Tumor site & & & 0.72 & & & 1 \\
\hline Colon & $44(35.2)$ & $67(33.2)$ & & 14 (35.9) & $30(34.9)$ & \\
\hline Rectum & $81(64.8)$ & $135(66.8)$ & & $25(64.1)$ & $56(65.1)$ & \\
\hline T stage & & & 0.458 & & & 0.523 \\
\hline $\mathrm{T} 1$ & $1(0.8)$ & $1(0.5)$ & & $0(0)$ & $1(1.2)$ & \\
\hline $\mathrm{T} 2$ & $4(3.2)$ & $9(4.5)$ & & $0(0)$ & $4(4.7)$ & \\
\hline $\mathrm{T} 3$ & $120(96)$ & $188(93.1)$ & & $39(100)$ & $81(94.2)$ & \\
\hline $\mathrm{T} 4$ & $0(0)$ & $4(2)$ & & $0(0)$ & $0(0)$ & \\
\hline N stage & & & 0.288 & & & 0.202 \\
\hline NO & $65(52)$ & $121(59.9)$ & & $20(51.3)$ & $45(52.3)$ & \\
\hline N1 & $41(32.8)$ & $60(29.7)$ & & $10(25.6)$ & $31(36)$ & \\
\hline N2 & $19(15.2)$ & $21(10.4)$ & & $9(23.1)$ & $10(11.6)$ & \\
\hline TNM stage & & & 0.167 & & & 1 \\
\hline$\|$ & $65(52)$ & $122(60.4)$ & & $20(51.3)$ & $45(52.3)$ & \\
\hline III & $60(48)$ & 80 (39.6) & & $19(48.7)$ & $41(47.7)$ & \\
\hline Histological types & & & 0.447 & & & 0.092 \\
\hline Adenocarcinoma & 107 (85.6) & $166(82.2)$ & & $31(79.5)$ & $78(90.7)$ & \\
\hline $\begin{array}{l}\text { Mucinous } \\
\text { adenocarcinoma }\end{array}$ & $18(14.4)$ & $36(17.8)$ & & $8(20.5)$ & $8(9.3)$ & \\
\hline Differentiation & & & 0.652 & & & 0.253 \\
\hline Well & $6(4.8)$ & $10(5)$ & & $1(2.6)$ & $5(5.8)$ & \\
\hline Moderately & 87 (69.6) & $152(75.2)$ & & $29(74.4)$ & $58(67.4)$ & \\
\hline Poorly & $19(15.2)$ & $22(10.9)$ & & $3(7.7)$ & 16 (18.6) & \\
\hline Not Available & $13(10.4)$ & $18(8.9)$ & & $6(15.4)$ & $7(8.1)$ & \\
\hline Neoadjuvant therapy & & & 1 & & & 0.501 \\
\hline Yes & $10(8)$ & $15(7.4)$ & & $4(10.3)$ & $6(7)$ & \\
\hline No & $115(92)$ & $187(92.6)$ & & 35 (89.7) & $80(93)$ & \\
\hline Retrieved LN & & & 0.173 & & & 0.663 \\
\hline$<12$ & $32(25.6)$ & $67(33.2)$ & & $11(28.2)$ & $21(24.4)$ & \\
\hline$\geq 12$ & $93(74.4)$ & $135(66.8)$ & & $28(71.8)$ & $65(75.6)$ & \\
\hline CEA $(\mathrm{ng} / \mathrm{ml})$ & & & 0.909 & & & 0.332 \\
\hline$\leq 5$ & $70(56)$ & $111(55)$ & & $19(48.7)$ & $51(59.3)$ & \\
\hline$>5$ & $55(44)$ & $91(45)$ & & $20(51.3)$ & $35(40.7)$ & \\
\hline CA19-9(U/ml) & & & 0.492 & & & 0.27 \\
\hline$\leq 37$ & 107 (85.6) & $179(88.6)$ & & $31(79.5)$ & $76(88.4)$ & \\
\hline$>37$ & $18(14.4)$ & $23(11.4)$ & & $8(20.5)$ & $10(11.6)$ & \\
\hline $\mathrm{ALT}(\mathrm{U} / \mathrm{L})$ & $17.65 \pm 9.50$ & $19.86 \pm 15.86$ & 0.377 & $18.41 \pm 9.85$ & $17.31 \pm 9.37$ & 0.434 \\
\hline $\mathrm{AST}(\mathrm{U} / \mathrm{L})$ & $18.42 \pm 6.70$ & $19.01 \pm 9.60$ & 0.892 & $18.10 \pm 6.12$ & $18.56 \pm 6.98$ & 0.94 \\
\hline $\operatorname{ALP}(U / L)$ & $83.90 \pm 21.67$ & $84.66 \pm 24.98$ & 0.86 & $82.56 \pm 20.30$ & $84.51 \pm 22.34$ & 0.643 \\
\hline
\end{tabular}


Table 1 Characteristics of the included patients (Continued)

\begin{tabular}{lllllll}
\hline Variable & $\begin{array}{l}\text { anti-HBc positive, } \boldsymbol{n} \\
\text { (\%) }\end{array}$ & $\begin{array}{l}\text { anti-HBc negative, } \boldsymbol{n} \\
(\%)\end{array}$ & $\begin{array}{l}\boldsymbol{P} \\
\text { value }\end{array}$ & $\begin{array}{l}\text { High-titer anti-HBc, } \boldsymbol{n} \\
(\%)\end{array}$ & $\begin{array}{l}\text { Low-titer anti-HBc, } \boldsymbol{n} \\
\text { (\%) }\end{array}$ & $\begin{array}{l}\boldsymbol{P} \\
\text { value }\end{array}$ \\
\hline $\mathrm{PLT}\left(1 \times 10^{9} / \mathrm{L}\right)$ & $252.90 \pm 67.98$ & $250.91 \pm 77.43$ & 0.622 & $261.97 \pm 67.56$ & $84.51 \pm 22.34$
\end{tabular}

Abbreviations: anti-HBC, antibodies to hepatitis B core antigen, CA19-9 cancer antigen 19-9, CEA carcinoembryonic antigen, ALT alanine transaminase, AST aspartate transaminase, $A L P$ alkaline phosphatase; PLT, platelets; LN, lymph node

*Significant at $P<0.05$

2.162-5.702; $P<0.001)$ were associated with worse OS; $\mathrm{NLR} \geq 3.4(\mathrm{HR}, 1.783 ; 95 \% \mathrm{CI}, 1.094-2.906 ; P=.02)$ and stage III (HR, 3.579; 95\% CI, 2.247-5.699; $P<.001)$ were associated with worse TTP; NLR $\geq 3.4$ (HR, 2.231; 95\% CI, 1.043-4.773; $P=.039$ ) and stage III (HR, 2.985; 95\% CI, 1.394-6.391; $P=.005)$ were associated with worse HMFS (Table 2). However, univariate and multivariate analyses for the anti-HBc positive CRC patients undergoing curative surgical resection revealed that anti-HBc $\geq 8.8$ (HR, 3.510; 95\% CI, 1.718-7.17; $P=.001$ ) and stage III (HR, 3.038; 95\% CI, 1.423-6.484; $P=.004$ ) were associated with worse OS; anti-HBc $\geq 8.8$ (HR, 5.747; 95\% CI, 2.789-11.842; $P<0.001)$ and stage III (HR, 3.722; 95\% CI, 1.752-7.908; $P<.001)$ were associated with worse TTP; only anti-HBc $\geq 8.8(\mathrm{HR}, 3.754 ; 95 \% \mathrm{CI}$, 1.054-13.369; $P=.041)$ was associated with worse HMFS (Table 3).

\section{Discussion}

In this study, we used anti-HBc, which is different from HBsAg used in previous studies, as a marker of HBV infection $[17,18]$, because using HBsAg as the criteria of grouping may lead to the grouping mistake by deeming occult hepatitis B infection as non-infected and generate significant deviation. After people get infected by HBV, a covalently closed circular DNA form (cccDNA) is deposited to serve as a template for the transcription of all HBV RNAs, the production of progeny virus [19] and
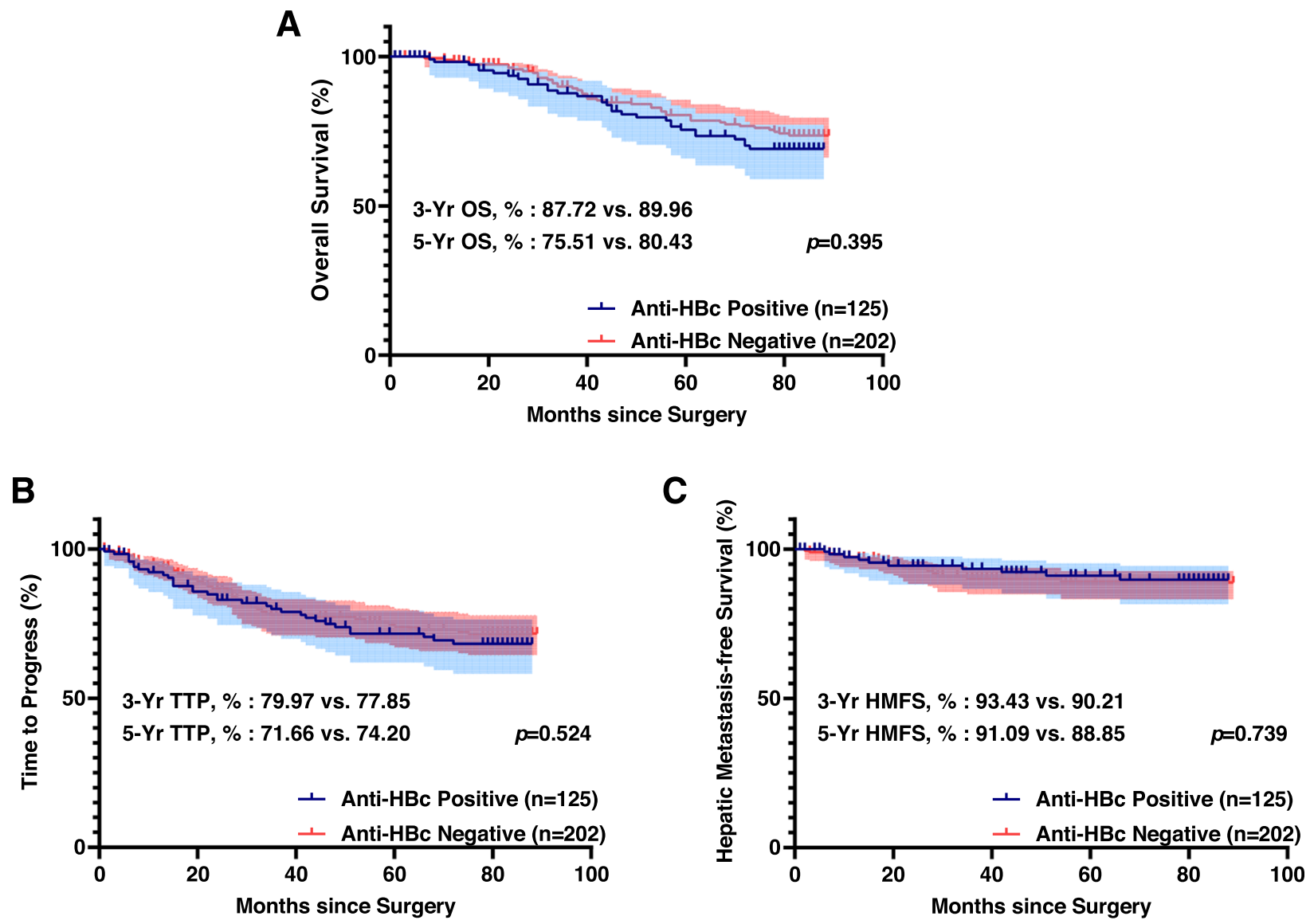

Fig. 1 Kaplan-Meier curves of overall survival (OS), time to progress (TTP), and hepatic metastasis-free survival (HMFS) between the anti-HBC positive group and anti-HBC negative group. A Overall survival curve. B Time to progress curve. C Hepatic metastasis-free survival curve. The light blue and red area represent $95 \%$ confidence intervals of each group. There is no significant difference between the two groups 

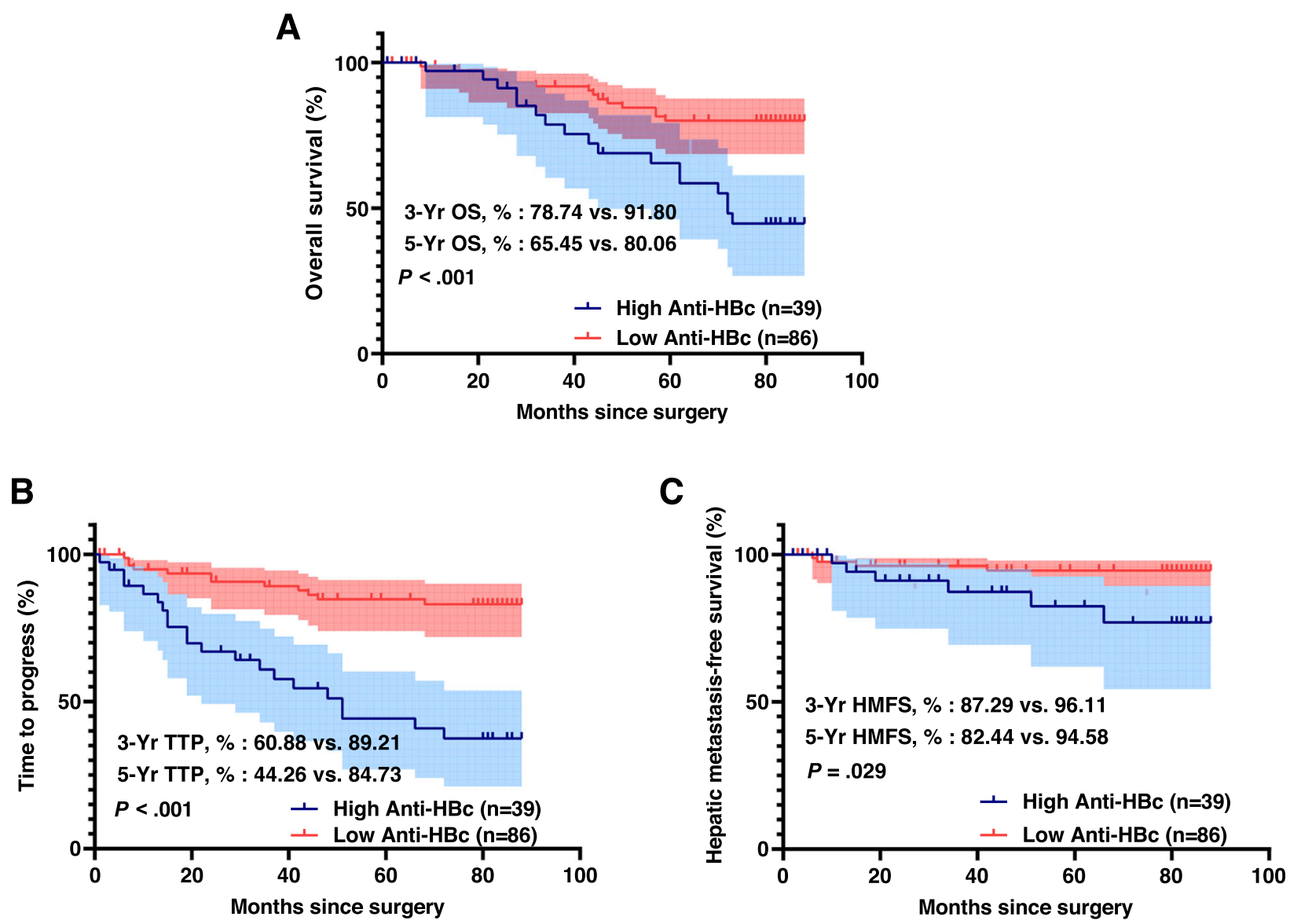

Fig. 2 Kaplan-Meier curves of overall survival (OS), time to progress (TTP), and hepatic metastasis-free survival (HMFS) between the high-titer antiHBC group and low-titer anti-HBC group. The light blue and red area represent 95\% confidence intervals of each group. Patients in the high-titer anti-HBC group had shorter OS, TTP, and HMFS than those in the low-titer anti-HBC group

conduct consistent inflammation of human body [20]. The cccDNA can be detected frequently in the liver of the HBsAg negative phase patients [21]. HBV can be hardly cured by available antivirals, because neither cccDNA nor relax circular DNA (rcDNA) is affected during the anti-viral process [19]. For this reason, the European Association for the Study of the Liver (EASL) and American Association for the Study of Liver Diseases (AASLD) termed the therapeutic goal of chronic hepatitis B (CHB) "functional cure," while the true cure is the elimination of cccDNA [21, 22]. Several studies have proved even HBV related hepatocellular carcinoma and complications of cirrhosis [23-25] can still occur in the resolved HBV patients when they are receiving immunosuppressive therapy.

Anti-HBc, generated by humoral immunity, is highly stable. After acute HBV infection, IgM class antibodies are firstly observed in the host's organism, and then anti-HBc IgG begins to appear. Over time, IgM levels gradually decline until they cannot be detected, and IgG can persist for 10 or even more than 20 years [11]. Anti-
$\mathrm{HBc}$ also has a relatively high specificity; it is produced in the presence of HBV infection rather than a serological response to HBV vaccination, while anti-HBs can appear in both situations. Therefore, anti-HBc was chosen to use as a serum marker for HBV infection in our study.

Our data showed no statistical difference between the anti-HBc positive group and anti-HBc negative group about the incidence of CRLM. Prior to this, Utsunomiya $\mathrm{T}$ et al. analyzed the association of hepatitis virus infection and the incidence of CRLM in 1999. He found that the incidence of CRLM of the infected group was significantly lower than non-infected group $(8.1 \%$ vs. $21.2 \%, P$ $<.05)$ [26]. However, the study did not analyze HBV and HCV separately. In 2001, Song E et al. found that the incidence of CRLM in patients with HBV infection was significantly lower than that in patients who are not infected $(13.5 \%$ vs. $27.1, P<.05)$, and the prognosis of infected patients was better [27].

Some studies reached the opposite conclusion. Huo T et al. performed a cross-sectional study about CRC 


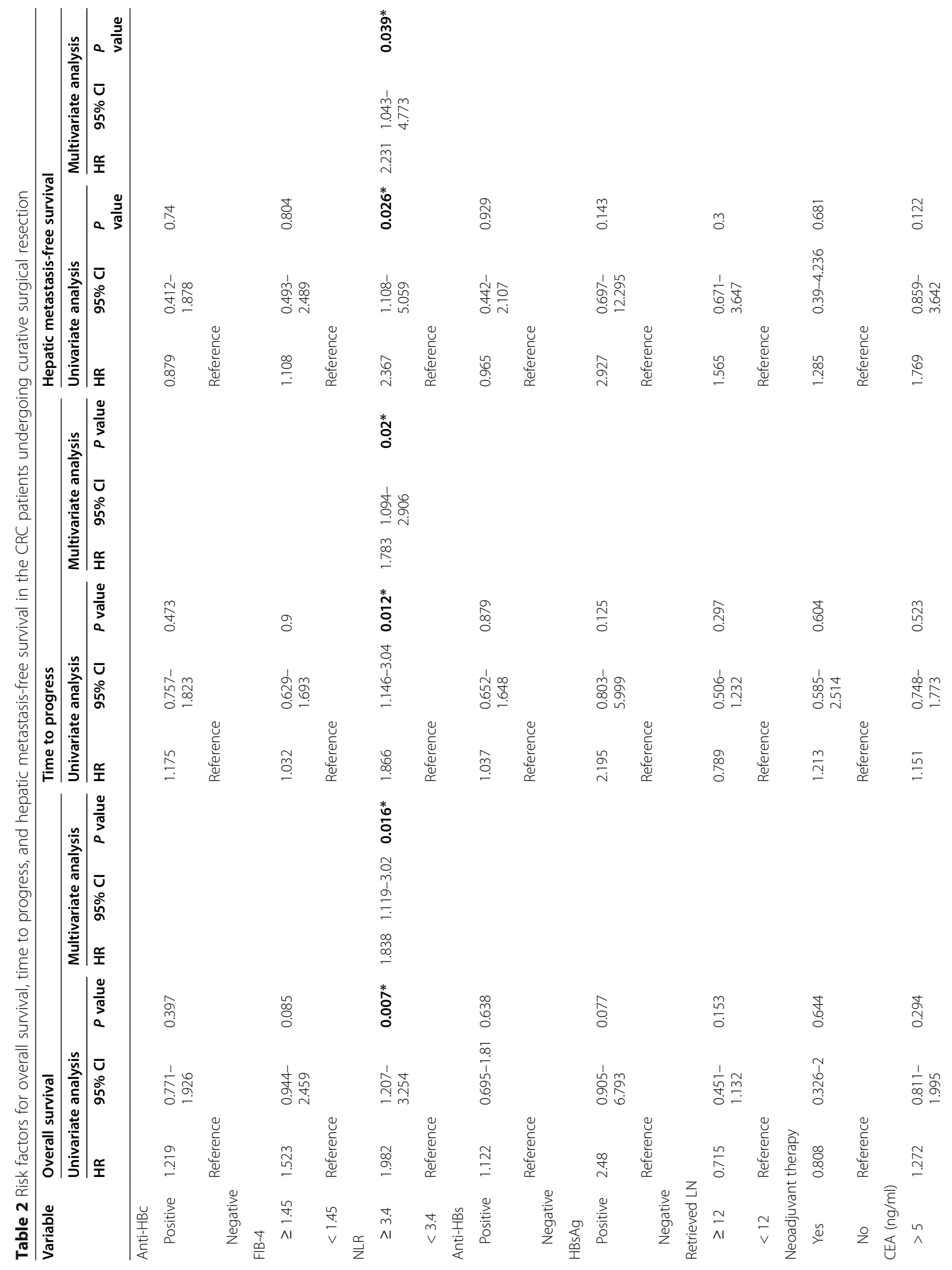




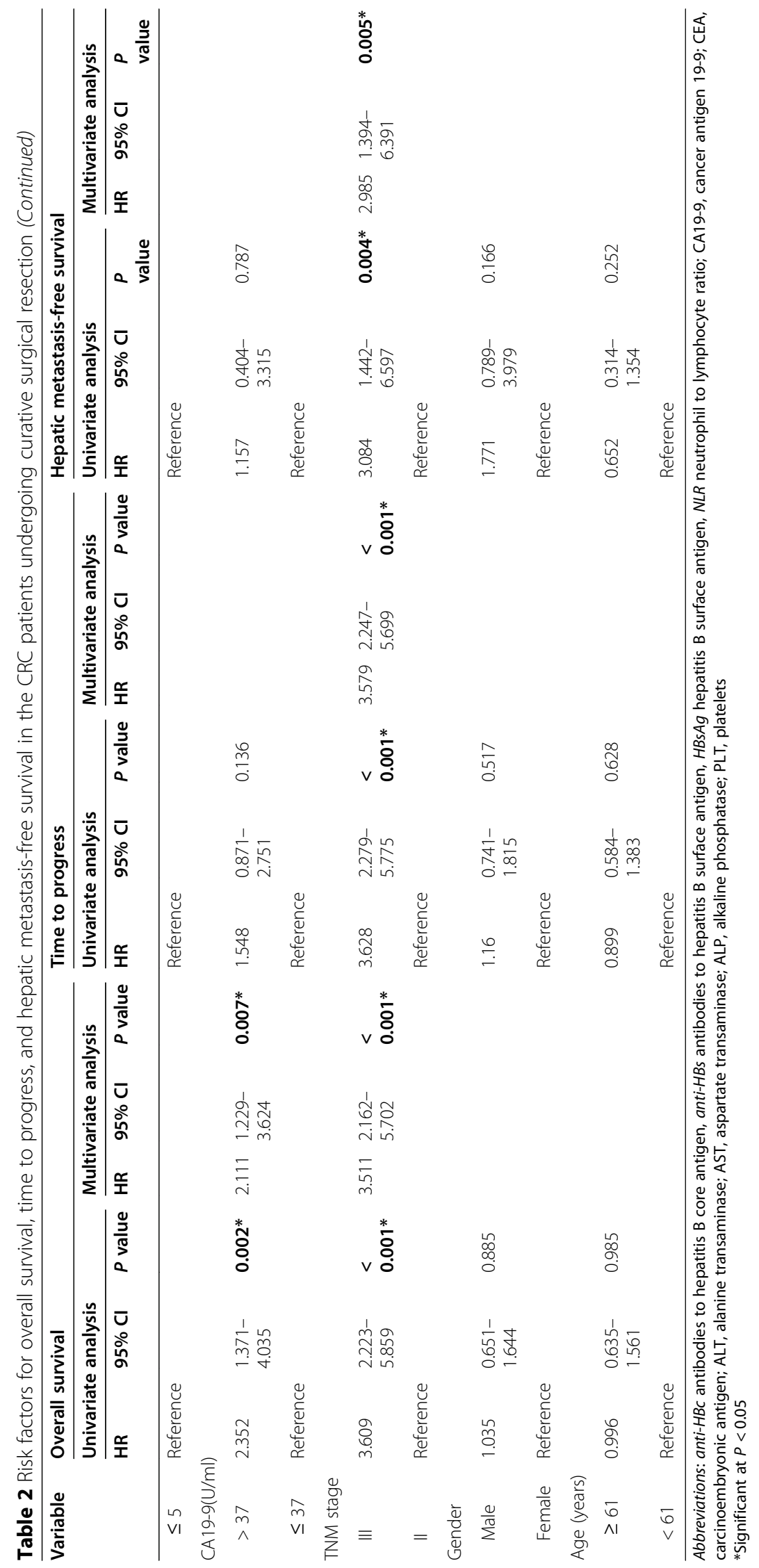




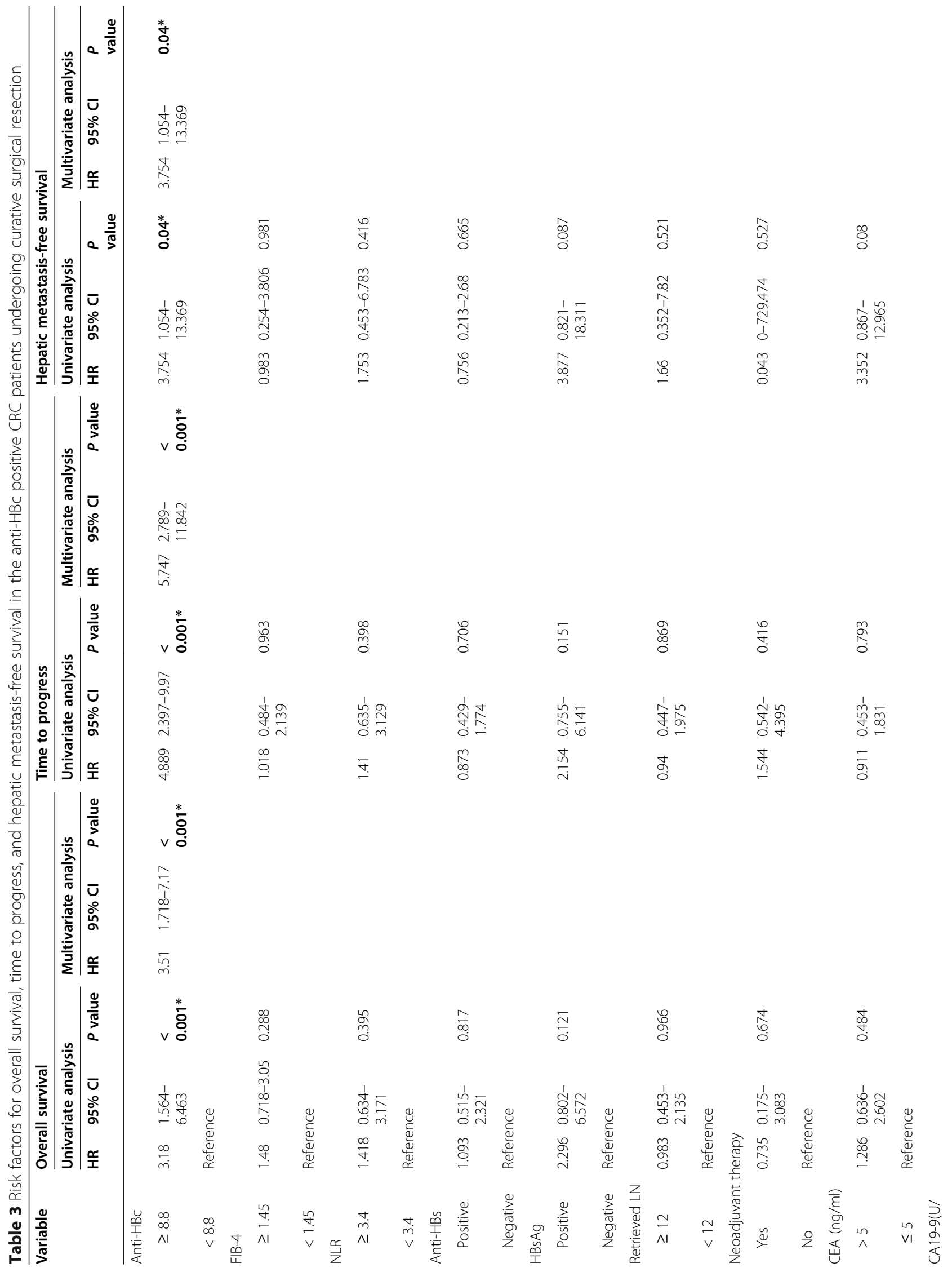


Li et al. World Journal of Surgical Oncology

(2021) 19:251

Page 10 of 14

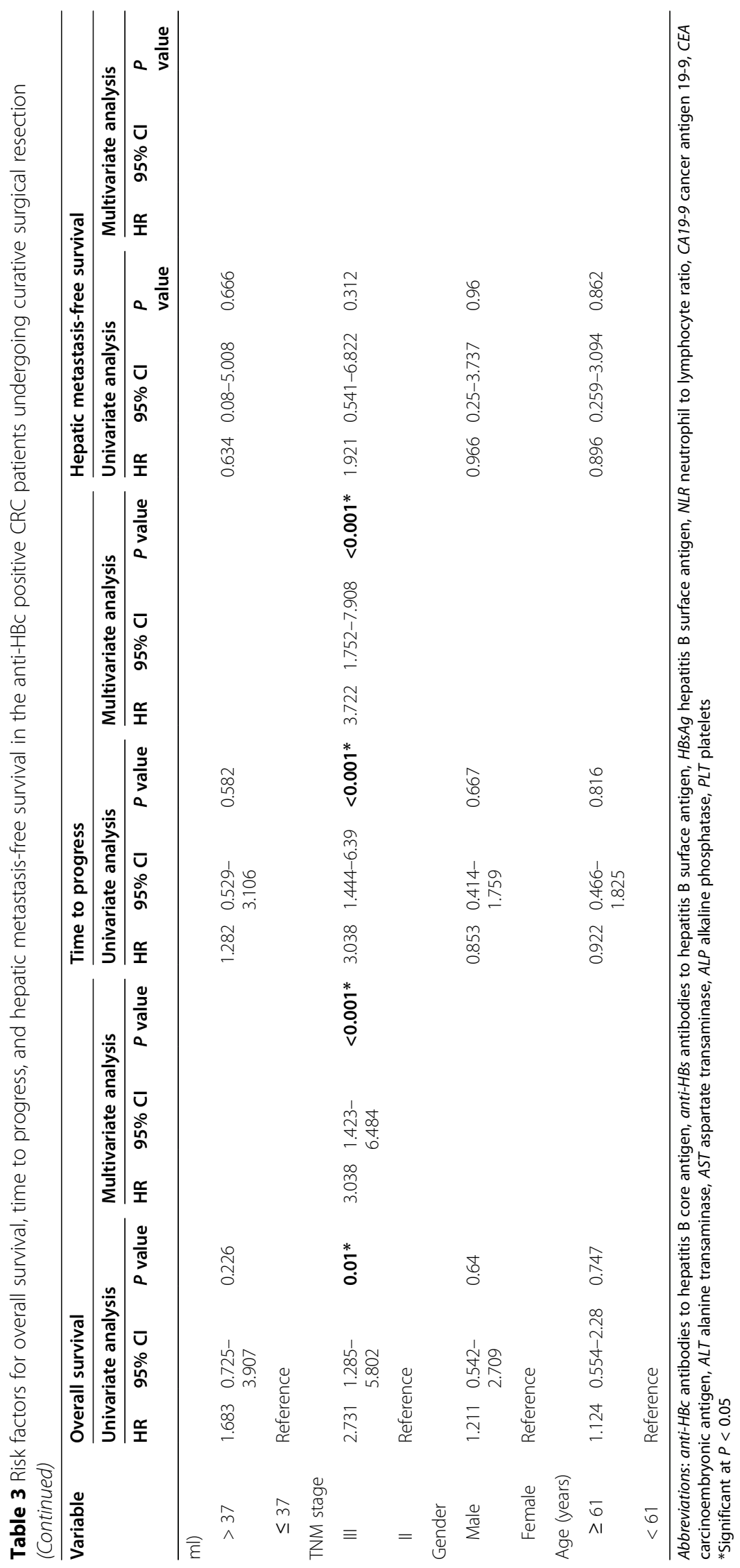


patients and reported that chronic HBV infection increased the risk of CRLM. Also, the study found that the incidence of CRLM of the HBeAg-positive patients was higher than it of the HBeAg-negative patients [18]. It indicated that activated replication of HBV could increase the risk of CRLM, although there are not any significant differences identified. A similar phenomenon was found in the study of Wei X et al. where the pancreatic cancer was included as the object of the study instead of CRC, and the phenomenon that the rate of liver metastases in CHB patients was higher than both uninfected patients and patients with resolved HBV infection $(61.1 \%$ vs. $33.9 \%, P<0.05$, and $61.1 \%$ vs. $28.7 \%, P<0.05$, respectively) [28] was observed.

Our outcome differs from previous studies. The probably reason is the recognition of HBV infection in our study differs from other studies in which "HBV infection" was characterized by positive HBsAg. Therefore, the composition of "HBV-infected patients" in this study varies from other studies. Also, $\mathrm{HBV}$ replication activity of anti-HBc positive cases varies from the "HBV-infected" cases in previous studies. Additionally, both Wei $\mathrm{X}$ and Huo $\mathrm{T}$ have observed a likely correlation between the activity of HBV replication and liver metastases of malignant tumors.

In 1974, Hoofnagle $\mathrm{JH}$ et al. [13] proposed that anti$\mathrm{HBc}$, particularly in high titers, would reflect active replication of HBV. In 1992, Hisao Iizuka et al. [29] observed that the detection rate of HBV DNA in blood units with high-titer anti-HBc was higher than that with low-titer anti-HBc, which conforms with Hoofnagle's conclusion. In general, the cccDNA which serves as the template for HBV replication and transcription can directly reflect the intrahepatic activity of HBV replication. Unfortunately, the liver biopsy, which is indispensable for the quantitative analysis of cccDNA, cannot be carried out in this study.

It is worth mentioning that Caviglia GP et al. [12] reported the correlation between anti-HBc and cccDNA. They found that high-titer anti-HBc was associated with the finding of intrahepatic HBV cccDNA, while low-titer anti-HBc could exclude the presence of cccDNA. So, we conducted a subset analysis concerning the titer of anti$\mathrm{HBc}$, in which anti-HBc positive group was divided into the high-titer anti-HBc group and low-titer anti-HBc group. We found that higher titer anti-HBc predicts a higher risk of CRLM and worse survival. The possible explanations for this phenomenon are listed below. (1) HBV may promote the development of CRC by HBxmediated miR-34a downregulation which was observed in the research about the HBV-related HCC [30], and the miR-34 family was found to have antitumor activity, especially miR-34a, which was reported to promote CRC when it was downregulated [31, 32]. (2) HBV may promote CRC by altering the human gut microbiome which plays an important role in the development of CRC [33-35]. Due to the existence of the hepatointestinal axis, studies have shown that HBV affects the development of $\mathrm{HCC}$ by changing the intestinal flora [36], but whether this mechanism can be applied to CRLM needs to be further studied. However, Qin N et al. [37]. reported that in the patients with liver cirrhosis, the abundance of Lachnospiraceae which could inhibit the development of CRC by producing butyric acid was decreased [35, 38], while there was an increase in the Fusobacterium which could promote CRC by upregulating tumor-associated macrophages (TAMs) $[39,40]$.

Some previous studies suggest that cirrhosis could inhibit CRLM. As early as 1975, Hamaya K et al. [41] conducted several autopsies and observed the incidence of liver metastases in cirrhotics was lower than noncirrhotics $(26.3 \%$ vs. $43.2 \%)$. A series of subsequent studies have reached similar conclusions [42, 43]. This is probably because under the stimulation of pathogenic factors such as inflammation, the liver gradually gets fibrotic until pseudo-lobules are formed, which leads to the tortuous deformation of intrahepatic small vessels, and afterward hemodynamics changes of the liver occur. Moreover, the sinusoid capillarization causes transformations of adhesion factors and extracellular matrix, which is not conducive to the growth of tumor cells in the liver. Furthermore, the expression level of MMP inhibitors in the cirrhotic liver is also higher, which may be another component that inhibits the formation of CRLM in cirrhotic cases. However, there is no more convincing explanation for this phenomenon so far [43].

In this study, we used FIB-4 as predictors of fibrosis to evaluate its impact on CRLM. But no statistical difference was identified. This is probably because in spite of 81 cases with FIB- $4>1.45$ was identified, 77 cases of them were in the 1.45-3.25 interval which was not clearly defined so far [44], and only 4 cases were in the FIB-4 > 3.25 interval which corresponds to F3 and F4 (also known as advanced fibrosis) in the Metavir stage classification system. Besides, as an indirect indicator of liver fibrosis [14, 15], the accuracy of FIB-4 is not as good as the liver biopsy. It is worth mentioning that the liver biopsy, an invasive inspection, was not routinely performed before the colorectomy, except that cirrhosisrelated symptoms occurred.

We found that NLR $\geq 3.4$, CA19-9 $>37 \mathrm{U} / \mathrm{ml}$, and stage III were the predictors of adverse outcomes, which strongly support previous reports [45-54] and clinical experience.

There are several limitations in our approach. First, this is a retrospective single-institution study with relatively small sample size and multi-center, prospective, large-scale trials are needed in the future. Second, some 
clinical data such as serum HBV DNA, intrahepatic HBV DNA, and cccDNA were not available in the study. As a retrospective study, we are unable to obtain these data. Finally, we did not analyze the usage of antivirals which may affect the outcomes.

Of note, we developed a basis for understanding the relationship between HBV infection, prognosis, and liver metastases in CRC patients using anti-HBc as the criterion for distinguishing $\mathrm{HBV}$ infection, avoiding errors generated by using $\mathrm{HBsAg}$ as the criterion for grouping. Moreover, we first established a link between the anti$\mathrm{HBc}$ titer and the prognosis and liver metastases of CRC patients. Notably, we excluded patients who were infected with HAV, HCV, and HEV and patients with liver metastases before surgery to ensure the uniformity of baseline data to the greatest extent.

\section{Conclusion}

Our data demonstrated that higher titer anti-HBc predicts a higher risk of liver metastases and worse survival in anti-HBc positive patients with colorectal cancer undergoing curative surgical resection, which implies the close relationship between highly active replication of HBV and occurrence of CRLM. This gives us some enlightenment on the management of CRC patients. For the management of CRC, we should pay more attention to the status of $\mathrm{HBV}$, especially those whose serum anti$\mathrm{HBc}$ are above $8.8 \mathrm{~S} / \mathrm{CO}$, because this may pose great impact to improving the prognosis of such patients. Moreover, we can draw up more personalized follow-up plans for patients based on their anti-HBc titers.

\section{Supplementary Information}

The online version contains supplementary material available at https://doi. org/10.1186/s12957-021-02369-1.

Additional file 1: Supplementary Figure 1. Flow diagram of the retrospective analysis with adequate data.

Additional file 2: Supplementary Figure 2. X-tile plots of the anti$\mathrm{HBC}$. Notes: $X$-tile plots showing $X 2$ values with cut-off points to generate the low-titer and high-titer anti-HBc subgroups. (A) The optimal cutoff value of the anti-HBC was 8.8 at the maximum $x 2$ value of 18.44. (B) Histogram of the entire cohort divided into low-titer anti-HBC and hightiter anti-HBC subgroups according to the optimal cutoff value of 8.8. Blue bars represent the low-titer anti-HBc group, and gray bars represent the high-titer anti-HBc group.

\section{Acknowledgements}

I would like to thank Tong Wang and Jin Li for their support of data collection.

\section{Authors' contributions}

Ziyao Li: study concept and design, data acquisition, analysis, and interpretation of data, drafting of the manuscript, manuscript review; Guoxun Li: study concept and design, data acquisition, analysis, and interpretation of the data, drafting of the manuscript, manuscript review. Shaofei Li, Hangbo Tao, Yixiang Zhan, Kemin Ni: data acquisition, study conception, and manuscript review. Jianfeng Gong, study supervision. All authors approved the final version of the article, including the authorship list.

\section{Funding}

The study was funded by The National Natural Science Foundation of China (grant number 81970469).

\section{Availability of data and materials}

The datasets used and/or analyzed during the current study are available from the corresponding author on reasonable request.

\section{Declarations}

\section{Ethics approval and consent to participate}

This study was approved by the Hospital Review Board of Tianjin Union Medical Center, and the study was conducted following the ethical standards of the Declaration of Helsinki. The follow-up data was obtained from the follow-up system of Tianjin Union Medicine Center which did not involve any identification data, and the confidentiality of patient information was maintained. So, the Review Board of Tianjin Union Medicine Center waived the need for informed patient consent.

\section{Consent for publication}

Not applicable.

\section{Competing interests}

The authors declare no competing interests.

\section{Author details}

${ }^{1}$ Department of Colorectal Surgery, Tianjin Union Medical Center, No. 190 Jieyuan street, Hongqiao District, Tianjin 300121, China. ${ }^{2}$ School of Medicine, Nankai University, Tianjin 300071, China. ${ }^{3}$ Department of General Surgery, Jinling Hospital, Medical School of Nanjing University, Nanjing, China.

Received: 7 June 2021 Accepted: 12 August 2021

Published online: 26 August 2021

\section{References}

1. Sung H, Ferlay J, Siegel RL, Laversanne M, Soerjomataram I, Jemal A, et al. Global cancer statistics 2020: GLOBOCAN estimates of incidence and mortality worldwide for 36 cancers in 185 countries. CA Cancer J Clin. 2021; 71(3):209-49. https://doi.org/10.3322/caac.21660.

2. American Cancer Society. Cancer Facts \& Figures 2021. Atlanta: American Cancer Society; 2021. Available online: https://www.cancer.org/content/da $\mathrm{m} /$ cancer-org/research/cancer-facts-and-statistics/annual-cancer-facts-andfigures/2021/cancer-facts-and-figures-2021.pdf. Accessed July 2021.

3. Fernandez MC, Rayes R, Ham B, Wang N, Bourdeau F, Milette S, et al. The type I insulin-like growth factor regulates the liver stromal response to metastatic colon carcinoma cells. Oncotarget. 2017;8(32):52281-93. https:// doi.org/10.18632/oncotarget.12595.

4. Virchow R. An address on the value of pathological experiments. Br Med J. 1881;2(1075):198-203. https://doi.org/10.1136/bmj.2.1075.198.

5. Hanahan D, Weinberg RA. Hallmarks of cancer: the next generation. Cell. 2011;144(5):646-74. https://doi.org/10.1016/j.cell.2011.02.013.

6. Mantovani A, Allavena P, Sica A, Balkwill F. Cancer-related inflammation. Nature. 2008;454(7203):436-44. https://doi.org/10.1038/nature07205.

7. Trinchieri G. Cancer immunity: lessons from infectious diseases. J Infect Dis. 2015;212(Suppl 1):S67-73. https://doi.org/10.1093/infdis/jiv070.

8. Peinado $H$, Zhang $H$, Matei IR, Costa-Silva B, Hoshino A, Rodrigues $G$, et al. Pre-metastatic niches: organ-specific homes for metastases. Nat Rev Cancer. 2017;17(5):302-17. https://doi.org/10.1038/nrc.2017.6

9. Psaila B, Lyden D. The metastatic niche: adapting the foreign soil. Nat Rev Cancer. 2009;9(4):285-93. https://doi.org/10.1038/nrc2621.

10. Ott JJ, Stevens GA, Groeger J, Wiersma ST. Global epidemiology of hepatitis $B$ virus infection: new estimates of age-specific HBsAg seroprevalence and endemicity. Vaccine. 2012;30(12):2212-9. https://doi.org/10.1016/j.vaccine.2 011.12.116.

11. Song LW, Liu PG, Liu CJ, Zhang TY, Cheng XD, Wu HL, et al. Quantitative hepatitis $B$ core antibody levels in the natural history of hepatitis $B$ virus infection. Clin Microbiol Infect. 2015;21(2):197-203. https://doi.org/10.1016/j. cmi.2014.10.002

12. Caviglia GP, Abate ML, Tandoi F, Ciancio A, Amoroso A, Salizzoni M, et al. Quantitation of HBV cccDNA in anti-HBc-positive liver donors by droplet 
digital PCR: a new tool to detect occult infection. J Hepatol. 2018;69(2):3017. https://doi.org/10.1016/j.jhep.2018.03.021.

13. Hoofnagle JH, Gerety RJ, Ni LY, Barker LF. Antibody to hepatitis B core antigen. A sensitive indicator of hepatitis B virus replication. N Engl J Med. 1974;290(24):1336-40. https://doi.org/10.1056/NEJM197406132902402.

14. Chen B, Ye B, Zhang J, Ying L, Chen Y. RDW to platelet ratio: a novel noninvasive index for predicting hepatic fibrosis and cirrhosis in chronic hepatitis B. PLoS One. 2013;8(7):e68780. https://doi.org/10.1371/journal.pone. 0068780 .

15. Vallet-Pichard A, Mallet V, Nalpas B, Verkarre V, Nalpas A, Dhalluin-Venier V, et al. FIB-4: an inexpensive and accurate marker of fibrosis in HCV infection. Comparison with liver biopsy and fibrotest. Hepatology. 2007:46(1):32-6. https://doi.org/10.1002/hep.21669.

16. Xiao WK, Chen D, Li SQ, Fu SJ, Peng BG, Liang L. Prognostic significance of neutrophil-lymphocyte ratio in hepatocellular carcinoma: a meta-analysis. BMC Cancer. 2014;14(1):117. https://doi.org/10.1186/1471-2407-14-117.

17. Au KP, Chok K, Chan A, Dai WC, Cheung TT, Lo CM. Impact of hepatitis B carrier status on the outcomes of surgical treatment of colorectal liver metastases. World J Surg. 2018;42(8):2642-50. https://doi.org/10.1007/s002 68-018-4483-3

18. Huo T, Cao J, Tian Y, Shi X, Wu L, Zhang M, et al. Effect of concomitant positive hepatitis B surface antigen on the risk of liver metastasis: a retrospective clinical study of 4033 consecutive cases of newly diagnosed colorectal cancer. Clin Infect Dis. 2018;66(12):1948-52. https://doi.org/10.1 093/cid/cix1118.

19. Lucifora J, Protzer U. Attacking hepatitis B virus cccDNA--the holy grail to hepatitis B cure. J Hepatol. 2016;64(1 Suppl):S41-8. https://doi.org/10.1016/j. jhep.2016.02.009.

20. Dong J, Ying J, Qiu X, Lu Y, Zhang M. Advanced strategies for eliminating the cccDNA of HBV. Dig Dis Sci. 2018;63(1):7-15. https://doi.org/10.1007/s1 0620-017-4842-1.

21. European Association for the Study of the Liver. Electronic address: ea sloffice@easloffice.eu, European Association for the Study of the liver. EASL 2017 clinical practice guidelines on the management of hepatitis B virus infection. J Hepatol 2017. 67(2): 370-398, DOl: https://doi.org/10.1016/j.jhep.2 017.03.021.

22. Terrault NA, Lok A, McMahon BJ, Chang KM, Hwang JP, Jonas MM, et al. Update on prevention, diagnosis, and treatment of chronic hepatitis B: AASLD 2018 hepatitis B guidance. Hepatology. 2018;67(4):1560-99. https:// doi.org/10.1002/hep.29800.

23. Yip TC, Chan HL, Wong WW, Tse YK, Lam KL, Wong GL. Impact of age and gender on risk of hepatocellular carcinoma after hepatitis B surface antigen seroclearance. J Hepatol. 2017;67(5):902-8. https://doi.org/10.1016/j.jhep.201 7.06.019.

24. Yip TC, Wong GL, Chan HL, Tse YK, Lam KL, Lui GC, et al. HBsAg seroclearance further reduces hepatocellular carcinoma risk after complete viral suppression with nucleos(t)ide analogues. J Hepatol. 2019;70(3):361-70. https://doi.org/10.1016/j.jhep.2018.10.014.

25. Yip TC, Wong GL, Wong WW, Tse YK, Lui GC, Lam KL, et al. Durability of hepatitis $B$ surface antigen seroclearance in untreated and nucleos $(t) i d e$ analogue-treated patients. J Hepatol. 2017.

26. Utsunomiya T, Saitsu H, Saku M, Yoshida K, Matsumata T, Shimada M, et al. Rare occurrence of colorectal cancer metastasis in livers infected with hepatitis B or C virus. Am J Surg. 1999;177(4):279-81. https://doi.org/10.101 6/S0002-9610(99)00045-8

27. Song E, Chen J, Ou Q, Su F. Rare occurrence of metastatic colorectal cancers in livers with replicative hepatitis B infection. Am J Surg. 2001; 181(6):529-33. https://doi.org/10.1016/S0002-9610(01)00634-1.

28. Wei XL, Qiu MZ, Chen WW, Jin Y, Ren C, Wang F, et al. The status of HBV infection influences metastatic pattern and survival in Chinese patients with pancreatic cancer. J Transl Med. 2013;11(1):249. https://doi.org/10.1186/1479-5876-11-249.

29. lizuka H, Ohmura K, Ishijima A, Satoh K, Tanaka T, Tsuda F, et al. Correlation between anti-HBC titers and HBV DNA in blood units without detectable HBsAg. Vox Sang. 1992;63(2):107-11. https://doi.org/10.1111/j.1423-0410.1 992.tb02495.x.

30. Rana MA, ljaz B, Daud M, Tariq S, Nadeem T, Husnain T. Interplay of Wnt $\beta$ catenin pathway and miRNAs in HBV pathogenesis leading to HCC. Clin Res Hepatol Gastroenterol. 2019;43(4):373-86. https://doi.org/10.1016/.clinre.201 8.09.012.

31. Öner MG, Rokavec M, Kaller M, Bouznad N, Horst D, Kirchner T, et al. Combined inactivation of TP53 and MIR34A promotes colorectal cancer development and progression in mice via increasing levels of IL6R and PAl1. Gastroenterology. 2018;155(6):1868-82. https://doi.org/10.1053/j.ga stro.2018.08.011.

32. Cai R, Lu Q, Wang D. Construction and prognostic analysis of miRNA-mRNA regulatory network in liver metastasis from colorectal cancer. World I Surg Oncol. 2021;19(1):7. https://doi.org/10.1186/s12957-020-02107-z.

33. Coker OO, Nakatsu G, Dai RZ, Wu W, Wong SH, Ng SC, et al. Enteric fungal microbiota dysbiosis and ecological alterations in colorectal cancer. Gut. 2019;68(4):654-62. https://doi.org/10.1136/gutjnl-2018-317178.

34. Kang M, Martin A. Microbiome and colorectal cancer: unraveling hostmicrobiota interactions in colitis-associated colorectal cancer development. Semin Immunol. 2017;32:3-13. https://doi.org/10.1016/j.smim.2017.04.003.

35. Wu X, Wu Y, He L, Wu L, Wang X, Liu Z. Effects of the intestinal microbial metabolite butyrate on the development of colorectal cancer. J Cancer. 2018;9(14):2510-7. https://doi.org/10.7150/jca.25324.

36. Liu Q, Li F, Zhuang Y, Xu J, Wang J, Mao X, et al. Alteration in gut microbiota associated with hepatitis $B$ and non-hepatitis virus related hepatocellular carcinoma. Gut Pathog. 2019;11(1):1. https://doi.org/10.1186/ s13099-018-0281-6.

37. Qin N, Yang F, Li A, Prifti E, Chen Y, Shao L, et al. Alterations of the human gut microbiome in liver cirrhosis. Nature. 2014;513(7516):59-64. https://doi. org/10.1038/nature13568.

38. Louis $\mathrm{P}$, Hold GL, Flint HJ. The gut microbiota, bacterial metabolites and colorectal cancer. Nat Rev Microbiol. 2014;12(10):661-72. https://doi.org/10.1 038/nrmicro3344.

39. Kostic AD, Chun E, Robertson L, Glickman JN, Gallini CA, Michaud M, et al. Fusobacterium nucleatum potentiates intestinal tumorigenesis and modulates the tumor-immune microenvironment. Cell Host Microbe. 2013; 14(2):207-15. https://doi.org/10.1016/j.chom.2013.07.007.

40. Xue T, Yan K, Cai Y, Sun J, Chen Z, Chen X, et al. Prognostic significance of CD163+ tumor-associated macrophages in colorectal cancer. World J Surg Oncol. 2021;19(1):186. https://doi.org/10.1186/s12957-021-02299-y.

41. Hamaya K, Hashimoto H, Maeda Y. Metastatic carcinoma in cirrhotic liverstatistical survey of autopsies in Japan. Acta Pathol Jpn. 1975;25(2):153-9. https://doi.org/10.1111/j.1440-1827.1975.tb00854.X.

42. Cai B, Liao K, Song XQ, Wei WY, Zhuang Y, Zhang S. Patients with chronically diseased livers have lower incidence of colorectal liver metastases: a meta-analysis. PLoS One. 2014;9(9):e108618. https://doi.org/1 0.1371/journal.pone.0108618

43. Ramia JM, López-Andujar R, Torras J, Falqueras L, Gonzalez JA, Sanchez B, et al. Multicentre study of liver metastases from colorectal cancer in pathological livers. HPB (Oxford). 2011;13(5):320-3. https://doi.org/10.1111/ j.1477-2574.2010.00287.x.

44. Gounder PP, Haering C, Bruden D, Townshend-Bulson L, Simons BC, Spradling PR, et al. Does incorporating change in APRI or FIB-4 indices over time improve the accuracy of a single index for identifying liver fibrosis in persons with chronic hepatitis C virus infection. J Clin Gastroenterol. 2018. 52(1):60-6. https://doi.org/10.1097/MCG.0000000000000753.

45. Dexiang Z, Li R, Ye W, Haifu W, Yunshi Z, Qinghai Y, et al. Outcome of patients with colorectal liver metastasis: analysis of 1,613 consecutive cases. Ann Surg Oncol. 2012;19(9):2860-8. https://doi.org/10.1245/s10434-012-23 56-9.

46. Ying $\mathrm{HQ}$, Deng $\mathrm{QW}$, He BS, et al. The prognostic value of preoperative NLR, d-NLR, PLR and LMR for predicting clinical outcome in surgical colorectal cancer patients. Med Oncol. 2014;31:305.

47. Zhang J, Zhang HY, Li J, Shao XY, Zhang CX. The elevated NLR, PLR and PLT may predict the prognosis of patients with colorectal cancer: a systematic review and meta-analysis. Oncotarget. 2017;8(40):68837-46. https://doi.org/1 0.18632 /oncotarget. 18575.

48. Kuo YT, Tsai WS, Hung HY, Hsieh PS, Chiang SF, Lai CC, et al. Prognostic value of regional lymph node involvement in patients with metastatic colorectal cancer: palliative versus curative resection. World I Surg Oncol. 2021;19(1):150. https://doi.org/10.1186/s12957-021-02260-z.

49. Liao CK, Yu YL, Lin YC, Hsu YJ, Chern YJ, Chiang JM, et al. Prognostic value of the C-reactive protein to albumin ratio in colorectal cancer: an updated systematic review and meta-analysis. World J Surg Oncol. 2021;19(1):139. https://doi.org/10.1186/s12957-021-02253-y.

50. Lai IL, You JF, Chern YJ, Tsai WS, Chiang JM, Hsieh PS, et al. The risk factors of local recurrence and distant metastasis on pT1/T2NO mid-low rectal cancer after total mesorectal excision. World J Surg Oncol. 2021;19(1):116. https://doi.org/10.1186/s12957-021-02223-4. 
51. van den Berg I, van den Braak RR, van Vugt JL, ljzermans JN, Buettner S. Actual survival after resection of primary colorectal cancer: results from a prospective multicenter study. World J Surg Oncol. 2021;19:96.

52. Luo T, Wang Y, Shan X, Bai Y, Huang C, Li G, et al. Nomogram based on homogeneous and heterogeneous associated factors for predicting distant metastases in patients with colorectal cancer. World J Surg Oncol. 2021; 19(1):30. https://doi.org/10.1186/s12957-021-02140-6.

53. Ono K, Abe T, Oshita A, Sumi Y, Yano T, Okuda H, et al. Efficacy of upfront hepatectomy without neoadjuvant chemotherapy for resectable colorectal liver metastasis. World J Surg Oncol. 2021;19(1):97. https://doi.org/10.1186/ s12957-021-02210-9.

54. Jin KM, Wang K, Bao Q, Wang HW, Xing BC. Liver resection for colorectal liver-limited metastases in elderly patients: a propensity score matching analysis. World J Surg Oncol. 2020;18(1):275. https://doi.org/10.1186/s12957020-02055-8.

\section{Publisher's Note}

Springer Nature remains neutral with regard to jurisdictional claims in published maps and institutional affiliations.

Ready to submit your research? Choose BMC and benefit from:

- fast, convenient online submission

- thorough peer review by experienced researchers in your field

- rapid publication on acceptance

- support for research data, including large and complex data types

- gold Open Access which fosters wider collaboration and increased citations

- maximum visibility for your research: over $100 \mathrm{M}$ website views per year

At BMC, research is always in progress.

Learn more biomedcentral.com/submissions 